\title{
INVESTIGATION OF CLOUDS AND CLOUD RADIATIVE FORCING ON THE WINDWARD SIDE OF THE MADAGASCAR MOUNTAIN CHAINS
}

\author{
Pooja Rana ${ }^{1,2, *}$, V. Sathiyamoorthy ${ }^{1}$ \\ ${ }^{1}$ Space Applications Centre, Ahmedabad, Gujarat \\ ${ }^{2}$ Gujarat University, Ahmedabad, Gujarat \\ puji1888@gmail.com
}

Commission V, SS: Atmosphere, Ocean, Weather and Climate

KEYWORDS: Cloud radiative forcing, Madagascar, Windward side, Leeward side, Cloud physical properties

\begin{abstract}
:
Clouds affect the radiative energy balance of the earth-atmosphere system by reflecting and trapping the radiation. The cooling occurs over the earth by reflecting the incoming solar radiation and warming by trapping the outgoing longwave terrestrial radiation. In this paper an attempt has been carried out to understand the clouds and cloud radiative forcing over the windward side of the Madagascar mountain chain. The study was carried out using the Clouds and Earth's Radiant Energy System (CERES) data June - September from 2000 to 2016. Over the windward side, clouds tend to cool whereas on the leeward side, clouds tend to warm marginally. During this period, peak value of shortwave cloud forcing and the longwave cloud forcing are $-45 \mathrm{Wm}^{-2}$ and $+15 \mathrm{Wm}^{-2}$ respectively. Generally, the clouds are restricted to low level in the windward side. We also examined the association between the cloud radiative forcing and cloud physical properties such as cloud optical depth, cloud, cloud top temperature and cover amount. The cloud optical depth $(-0.74$ correlation value $)$ and cloud cover amount $(-0.51$ correlation value) show better correlation with net cloud radiative cooling. The surface pressure of the Madagascar is also correlated with the net cooling over the windward side.
\end{abstract}

\section{INTRODUCTION}

Clouds are composed of liquid droplets and frozen ice particles suspended in the atmosphere. They form due to the saturation of water vapour in the air when the water vapour is cooled to its dew point. Clouds affect the radiation balance of the earth-atmosphere system (Rossow, 1996). Clouds block a fraction of the earth emitted longwave radiation from escaping to space and thereby causing a warming. On the other hand, clouds reflect a fraction of the incoming shortwave solar radiation back to space and thereby causing a cooling. The net effect of the clouds is either warming or cooling of the earthatmosphere system depending upon the balance between longwave warming and shortwave cooling. Cloud macro(cloud top height, cloud cover, cloud top temperature, etc.) and micro-physical (liquid-ice phase, cloud droplet size, etc.) properties play an important role in cloud-radiation interaction (Sathiyamoorthy et al., 2011).

Influence of the clouds on the earth's radiation budget can be studied using cloud radiative forcing (CRF) parameters. CRF is computed by finding the difference between clear-sky and total-sky radiative fluxes (Charlock and Ramanathan, 1985; Sathiyamoorthy et al, 2004). Several studies made attempts to estimate the net radiative effect of clouds with satellite measured radiation budget data (Hartmann, et al., 1986; Ramanathan, et al., 1989; Sathiyamoorthy et al., 2004; 2007; 2011). With the advent of satellite era, it is possible to measure the earth radiation budget at the top of atmosphere.

\footnotetext{
* Corresponding author
}

The concept of studying the role of clouds on earth radiation budget from satellite data started from the Earth Radiation Budget Experiment (ERBE, Barkstrom, 1984) followed by Scanner for Radiation Budget $(\mathrm{SaRaB})$ and Clouds and the Earth's Radiant Energy System (CERES) instruments. Kiehl and Ramanathan (1990), studied the Indonesian region during April 1985 using ERBE data and noted that there is a near balance between shortwave cloud radiative forcing (SWCRF) and longwave cloud radiative forcing (LWCRF) over the deep convective regions. Pai and Rajeevan (1998) examined the variation of net cloud radiative forcing (NCRF) in the tropical Indian ocean region using ERBE data and they suggested that the variation in cloud radiative forcing is strongly correlated with changes in high cloud amount but weakly correlated with changes in low or middle level cloud amounts. Many of the earlier studies on the NCRF in the tropics had focused their attention on the warm pool region and Asian monsoon region.

Kiehl (1994) suggested that tropical deep convective clouds neither cool nor warm in an average sense, i.e., cooling due to shortwave reflection is nearly balanced by warming due to longwave absorption. But Rajeevan and Srinivasan (2000) noted that the Indian summer monsoon clouds exert a net cooling effect which otherwise is unique in the tropical belt. They suggested that large amount of high level clouds found over this region with high optical depth may be the reason for the radiative cooling. Sathiyamoorthy et al (2004) suggested that the increased amount of high level clouds over the monsoon region may be due to blowing-off of deep convective cloud tops by upper tropospheric wind shear.

When winds encounter a mountain, they may be forced to ascend and thereby produce clouds due to adiabatic cooling if the air is sufficiently moist (Grossman and Durran, 1984). They are called as orographic clouds. Atmospheric stability plays an important role in shaping 
the orographic clouds. If the atmosphere is stable, orographic clouds may wrap around the mountain in the windward side and it's top. On the other hand, if the atmosphere is unstable, orographically lifted clouds may

observed that orographic clouds tend to exert a net radiative cooling. No major efforts have been taken to understand the characteristics of theses clouds and their radiative forcing. The island nation of Madagascar in the southern Indian ocean has a mountain chain running across the island from south to north (Fig.1). The mountain chain encompasses of Tsaratanana Massif in the north, Ankaratra Massif in the central parts and Ivakoany Massif in the south. During June to September months, clouds form over the eastern side of this mountain chain and adjoining east coast. In Fig.2, visible channel imagery of MODIS onboard Terra satellite for a typical day during June-September months (10 September 2016) is shown. On this Day, clouds are seen over the east coast of Madagascar and the eastern parts of mountain chain. The leeward is free from clouds. These clouds are found to exert a net cooling along the east coast of Madagascar. As Madagascar mountain chain is isolated from nearby land or orographic features of Africa, it is an ideal place to study the characteristics of the orographically generated clouds and their radiative forcing.

\section{DATA AND METHODOLOGY}

The study region is Madagascar and its surrounding oceanic region bound between $30^{\circ} \mathrm{S}-12^{\circ} \mathrm{S}$ latitudes and $35^{\circ} \mathrm{E}-55^{\circ} \mathrm{E}$ longitudes. Global 30 Arc-Second Elevation (GTOPO30) Digital Elevation Model (DEM) data available at $30 \mathrm{~km}$ spatial resolution is used to study the geographical features of the Madagascar. International Satellite Cloud Climatology Project (ISCCP, Rossow et al. 1996) monthly cloud dataset available at $1^{\circ}$ lon. $\times 1^{\circ}$ lat. spatial resolution is used to study the cloud physical properties. The ISCCP cloud data was obtained from http://isccp.giss.nasa.gov/. The cloud optical depth (COD) is one of the physical properties of cloud which measures the amount of solar radiation (at visible wavelength) attenuated by the clouds. The cloud top pressure (CTP) represents the pressure of the cloud top. The ISCCP used visible wavelengths to measure $\mathrm{COD}$ and Infrared wavelength for CTP. These two cloud physical properties (COD and CTP) are further used by ISCCP to classify different cloud types. Clouds with CTP more than $680 \mathrm{hPa}$ are classified as low clouds, CTP between $680 \mathrm{hPa}$ to 440 $\mathrm{hPa}$ as middle clouds, and clouds with CTP below $440 \mathrm{hPa}$ as high clouds. CERES monthly top of atmosphere cloud radiative forcing dataset available at http://ceres.larc.nasa.gov/ is used for the study (Wielicki et al. 1998). The European Centre for Medium-Range Weather Forecasts (ECMWF) Reanalysis-Interim (ERAInterim) monthly dataset available at $1^{\circ}$ lon. $\times 1^{\circ}$ lat. spatial resolution is used to study the meteorological conditions (Dee et al. 2011).

The top of atmosphere cloud radiative forcing has three components namely shortwave cloud radiative forcing (SWCRF), longwave cloud radiative forcing (LWCRF) and net cloud radiative forcing (NCRF). These three cloud forcing components are useful to measure the impact of clouds on earth radiation budget. grow deeper. Orographic clouds provide rainfall in the windward side of the mountain. The clouds thin out and dissipate in the leeward side of the mountain due to the atmospheric subsidence motion. Over the tropics, it is

$S W C R F=S W F l x_{c l r}-S W F l x$

where, $S W F l x_{c l r}$ and SWFLx are shortwave flux in clear-sky and all-sky conditions respectively at the top of the atmosphere. SWCRF is generally a negative quantity.

$L W C R F=L W F l x_{c l r}-L W F l x$

where $L W F l x_{c l r}$ and $L W F L x$ are longwave flux in clearsky and all-sky conditions respectively at the top of the atmosphere. LWCRF is generally a positive quantity.

NCRF is defined as the sum of SWCRF and LWCRF and whose sign depends upon the relative magnitudes of LWCRF and SWCRF.

$N C R F=S W C R F+L W C R F$.

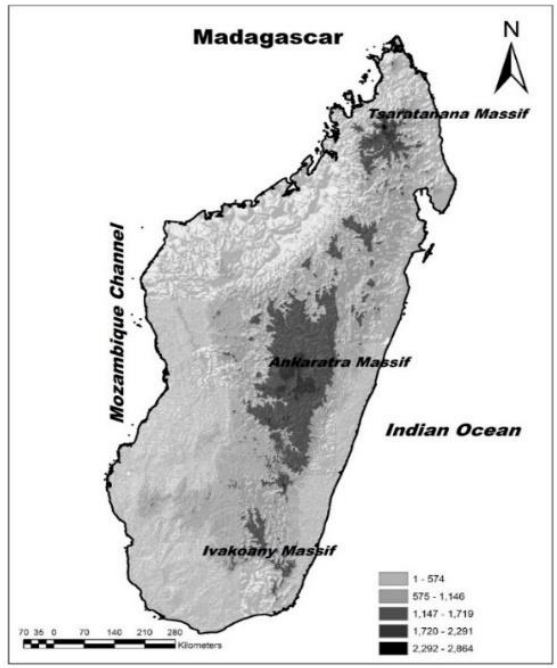

Figure 1. Elevation (m) map of Madagascar prepared using GTOPO-30 DEM data

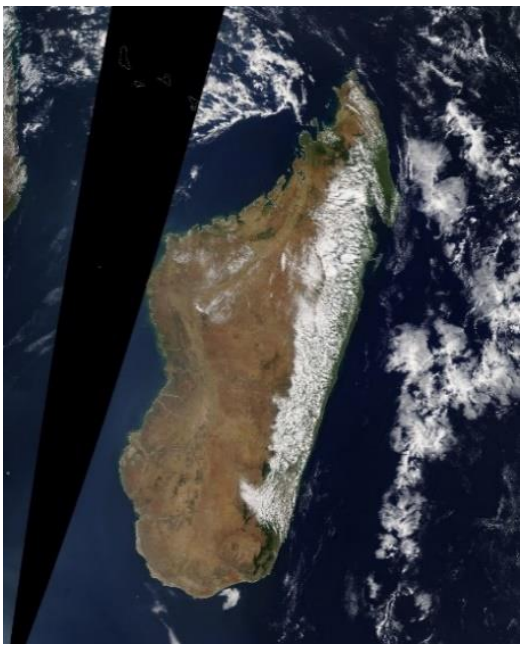

Figure 2. Visible channel imagery of MODIS onboard Terra satellite for the 10 September 2016 over the Madagascar and surrounding region 


\section{RESULTS}

\subsection{Low level atmospheric circulation over the Madagascar}

In Fig.3, 9 year (2000-2008) average low-level (975hPa) winds during June-September months over Madagascar and its surrounding $\left(31^{\circ} \mathrm{E}-55^{\circ} \mathrm{E}, 8^{\circ} \mathrm{S}-30^{\circ} \mathrm{S}\right)$ are shown. At this level, winds are stronger at the eastern and northern parts as compared to the western and southern parts of the study area. Winds are easterly or southeasterly on the eastern and northern parts. These strong winds are part of the southern hemispheric trade winds which upon reaching east African mountain chain strengthen and cross the equator and develop as Indian summer monsoon low level jet stream (Findlater,1969;1974). As the moisture laden easterly trades encounter the Madagascar mountain chain, lifted-up mechanically over the eastern parts of the mountain chain and adjoining east coast region during June to September months. anically and form orographic clouds over the eastern parts of the mountain chain and adjoining east coast region during June to September months.

\subsection{Cloud Physical Properties}

The 9-year average (2000-2008) monthly total cloud cover amount and cloud top pressure obtained from ISCCP cloud data during June to September (JJAS) months over the Madagascar and surrounding region (now onwards referred as the study region) have been shown in Fig.4 (a-b). The total cloud cover amount is about 40-60 $\%$ over the eastern side (windward side) while it is less than $30 \%$ over the western side (leeward side). The cloud top pressure is more (i.e., height is less) over the windward side of the Madagascar mountain chain. Cloud top pressure ranges from $550 \mathrm{hPa}-700 \mathrm{hPa}$ over the windward regions whereas it is less than $550 \mathrm{hPa}$ over the leeward side.

Further, 9-year average low, middle and high cloud cover amounts during June to September (JJAS) months are also shown from ISCCP cloud data in Fig.5. These figures suggest that the clouds over the Madagascar during JJAS is mostly low clouds with peak low clouds $(>30 \%)$ along the eastern parts of Madagascar. From Fig.3 and Fig.5, it is clear that the trade winds carry moisture from the Indian Ocean and upon approaching Madagascar mountains, they support cloud formation due to mechanical lifting and associated cooling.

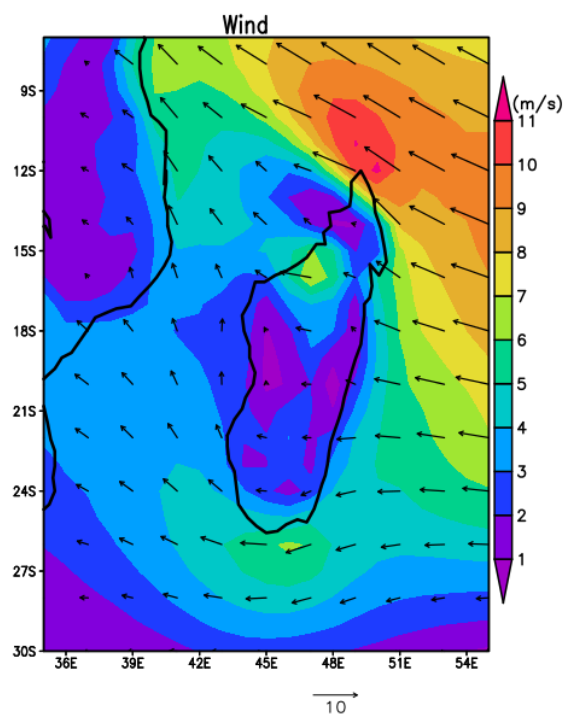

Figure 3. Nine year (2000-2008) average $975 \mathrm{hPa}$ wind $(\mathrm{m} / \mathrm{s})$ during June-September months from ERA data over the Madagascar and its surrounding
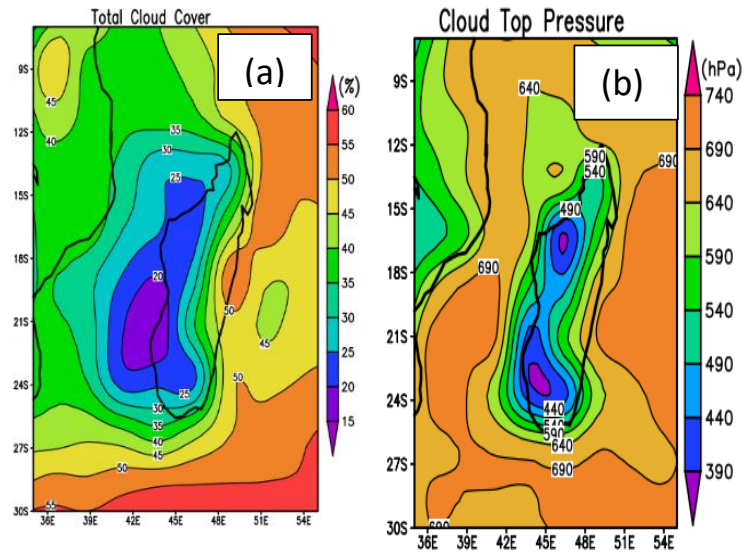

Figure 4. Nine-year (2008-2009) average (a) total cloud cover (\%) and (b) cloud top pressure (hPa) during June to September months over the study region
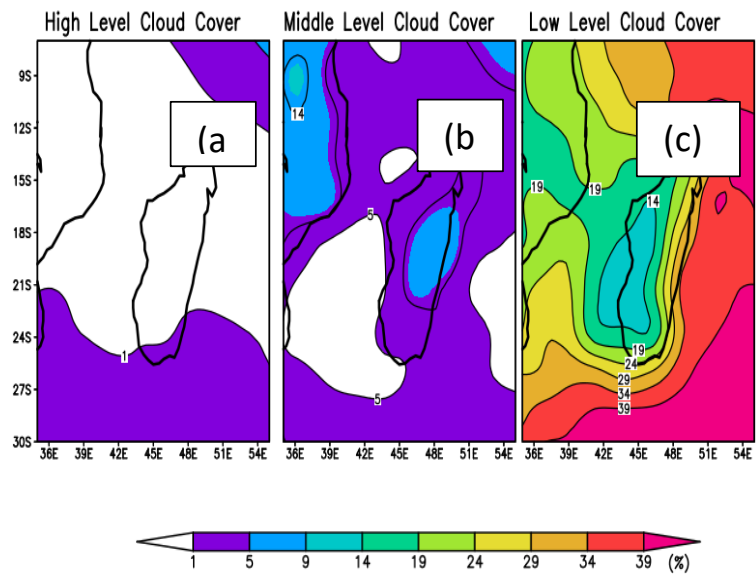

Figure 5. Nine year (2000-2008) average (a) High (b) Middle and (c) low level cloud covers (\%) during June to September months over the study region 


\subsection{Reasons Behind the Formation orographic clouds over Madagascar region}

In Fig.6a, nine year (2000-2008) average pressure vertical velocity, zonal wind speed and wind vector generated using zonal and vertical velocities along $18^{\circ} \mathrm{S}$ latitude across the study region are shown for $1000 \mathrm{hPa}$ to $200 \mathrm{hPa}$ levels. The Madagascar mountain chain is situated along $48^{\circ} \mathrm{E}$ longitude at this latitude cross section. The easterly trade winds are seen from surface to about $750 \mathrm{hPa}$ level. The trade winds (shown as contours) are as strong as $9 \mathrm{~m} / \mathrm{s}$ about $10^{\circ}$ longitude east of the mountain chain. As the winds approach the mountain, their speed decreases due to the blocking effect (Grossman and Durran, 1984). Shades suggests that upward motion (negative values) prevails on the windward side whereas downward motion (positive values) prevails in the leeward side of mountains. But the atmosphere is dominated by downward motion above $750 \mathrm{hPa}$. Though the upward motion supports cloud growth, these clouds are unable to grow deeper due to the presence of subsidence motion above. This may likely be the reason behind the formation of low clouds in the windward side of the Madagascar mountain chain. These clouds mostly wrap the windward side of the mountain rather than developing into a deep convective clouds.
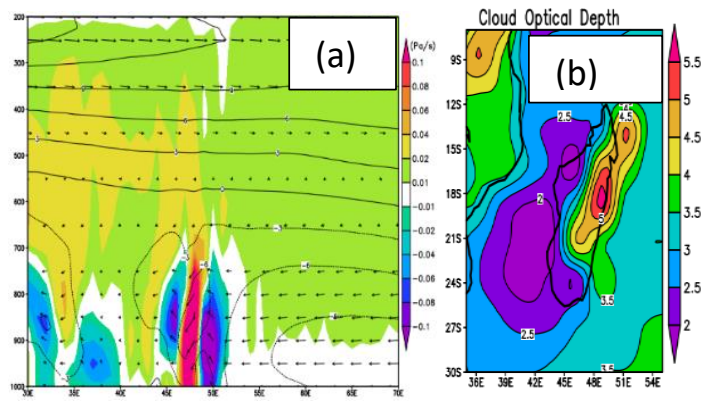

Figure 6. Nine year (2000-2008) average (a) pressure vertical velocity $(\mathrm{Pa} / \mathrm{s})$ in shades, zonal velocity $(\mathrm{m} / \mathrm{s})$ contour and vectors generated using zonal and vertical velocities during June to September along $18^{\circ} \mathrm{S}$ latitude. (b) Cloud optical depth (unit less) averaged during June to September of the nine-year study period

In Fig.6b, nine year (2000-2008) average cloud optical depth during JJAS is shown for the study region. The optical thickness of the clouds is more on the windward side and low on the leeward side. On the windward side, the COD is as high as 5.5. Blocking of the trade winds carrying moisture by the Madagascar mountain chain and associated increase in cloud water droplets may be the reason behind the increases in COD on the windward side of the mountain. As the subsidence is suppressing the cloud vertical growth, cloud droplets may not be able to grow bigger due to collision and coalition process. As the smaller water droplets are effective in reflecting incoming solar shortwave radiation, they may increase the COD.

\subsection{Cloud Radiative Forcing}

In Fig.7, 9 year (2000-2008) average SWCRF, LWCRF and NCRF during June to September months are shown for the study region. The LWCRF is about $5-10 \mathrm{Wm}^{-2}$ over the study region. As the orographic clouds are present at lower levels and the difference in the temperature between cloud top and the surface is less, they exert weak longwave warming effects. But the magnitude of SWCRF is comparatively more along the eastern (windward) side of the Madagascar mountain chain and adjoining east coast and less over the leeward side. The SWCRF is as low as $45 \mathrm{Wm}^{-2}$ over the windward side. As the magnitude of SWCRF is more than the LWCRF, the NCRF becomes negative. The NCRF is as low as $-35 \mathrm{Wm}^{-2}$ along the eastern parts of the mountain and the coastal area. This analysis suggests that the orographic clouds of the Madagascar exert a peak radiative cooling of about - 35 $\mathrm{Wm}^{-2}$ during the June to September months. Comparison of NCRF and COD images suggest that the spatial pattern of NCRF is closely matching with the spatial pattern of COD. Both have higher magnitude over the windward side and lower magnitude over the leeward side. We speculate that the increased COD windward side may be the reason for the incresed NCRF.

In Fig.8, the scatter plot between SWCRF and LWCRF is shown for rectangular region bounded between $-23^{\circ} \mathrm{S}$ to $12^{\circ} \mathrm{S}, 47^{\circ} \mathrm{E}$ to $51^{\circ} \mathrm{E}$ (East box). This plot is made using monthly CERES flux data of June to September months during 2000-2008. The scatter plot suggests the existence of imbalance between SWCRF and LWCRF over the east box region. The SWCRF varies between zero to $-80 \mathrm{Wm}^{-}$ ${ }^{2}$ whereas LWCRF varies between 0 to $30 \mathrm{Wm}^{-2}$. This causes the imbalance between shortwave cooling and longwave warming by clouds over the east box. This imbalance leads to the net cooling by clouds. The ratio between SWCRF and LWCRF is 2.74 .

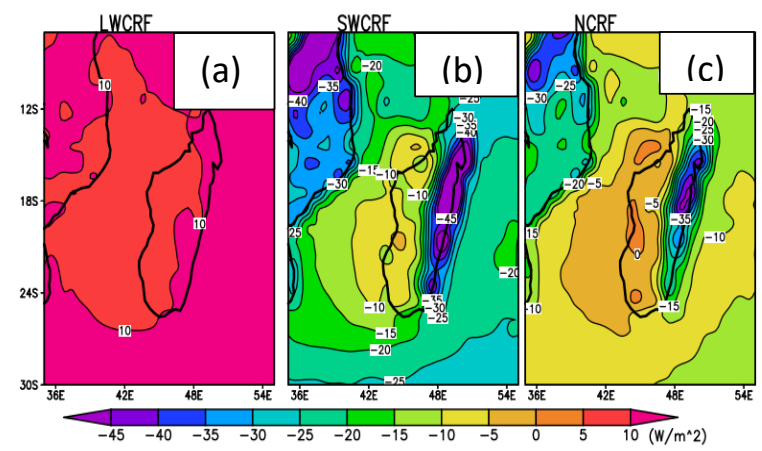

Figure 7. The 9-year (2000-2008) average (a) SWCRF $\left(\mathrm{Wm}^{-2}\right)$, (b) LWCRF $\left(\mathrm{Wm}^{-2}\right)$ and (c) NCRF $\left(\mathrm{Wm}^{-2}\right)$ during June-September months for the study region

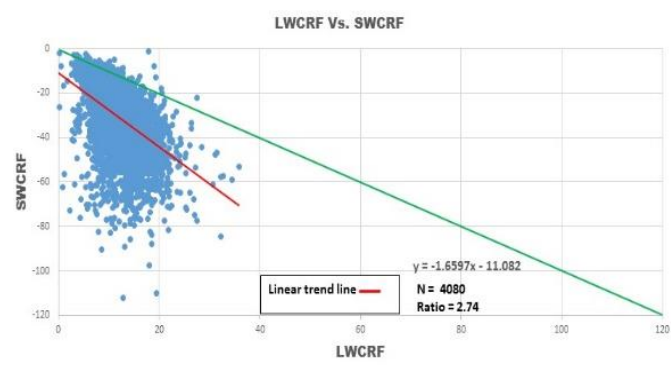

Figure 8. Scatter plot between monthly mean SWCRF $\left(\mathrm{Wm}^{-2}\right), \mathrm{LWCRF}\left(\mathrm{Wm}^{-2}\right)$ from the CERES at individual grid points over the east coast of Madagascar (JuneSeptember) of 2000-2008 
To further explore the relationship between COD and CRF components, scatter plots between monthly COD and CRF component (LWCRF, SWCR and NCRF) are plotted for the east box during June to September months of the 9year study period (Fig.9).

In Figure 9 scatter plots between monthly total cloud cover amount and SWRF/LWCRF/NCRF are shown for the east box during June to September of 2000-2008 period. The correlation between SWCRF and cloud cover amount (CCA) is -0.63. LWCRF showing a positive correlation of 0.58 . The correlation between CCA and NCRF is -0.52 .

Figure 9 Scatter plots between monthly mean cloud cover amount and SWRF/LWCRF/NCRF are shown for the east box during June to September of 2000-2008 period. The correlation between SWCRF and cloud cover amount (CCA) is -0.63. LWCRF showing a positive correlation of 0.58 . The correlation between CCA and NCRF is -0.52 .
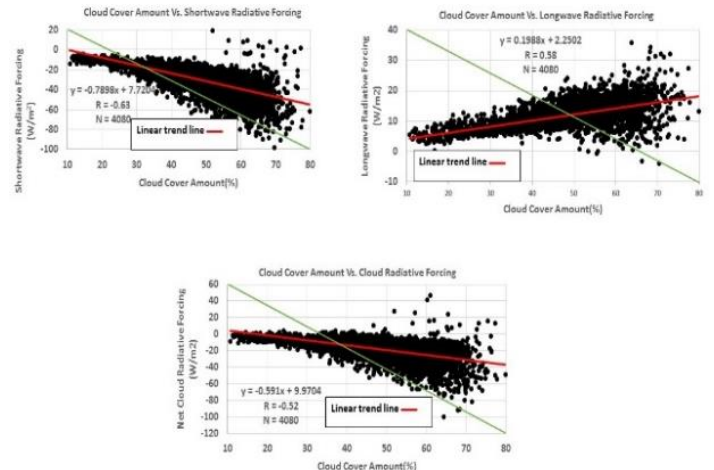

Figure 9. Scatter plots between monthly mean cloud cover amount (\%) with SWCRF, LWCRF, NCRF (Wm

${ }^{2}$ ) from the CERES over the east box during June to September months of 2000-2016

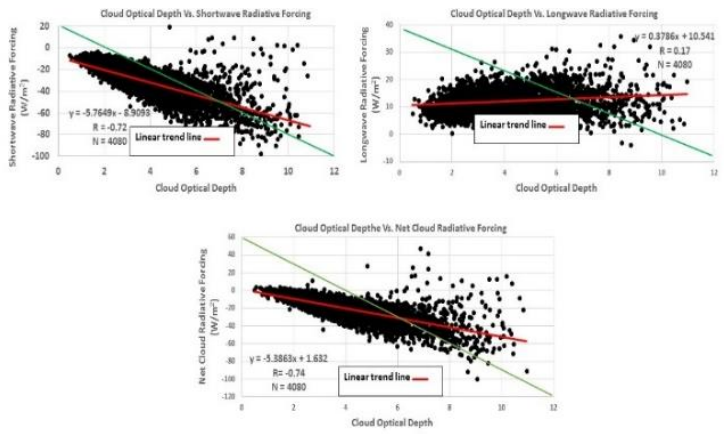

Figure 10. Scatter plots between monthly mean total cloud optical depth (unit less) with SWCRF, LWCRF, $\operatorname{NCRF}\left(\mathrm{Wm}^{-2}\right)$ from the CERES over the east box during June to September months of 2000-2008

Fig.10 suggests that SWCRF is negatively associated with the COD over the East box. The correlation between SWCRF and COD is - 0.72 . LWCRF is not showing any notable association with COD as evident from the scatter plot and the flat linear fit line. The correlation between COD and LWCRF is 0.17 . As the SWCRF is exhibiting association with COD, NCRF is also associated with COD. The correlation between COD and NCRF is -0.74 which is statistically significant at $99 \%$ confidence level.
So the scatter plots suggest that CRF components are related to the changes in CCA and COD over the east box.

\subsection{Relative Influence of Cloud Cover and Cloud Optical Depth on CRF Components}

Previous analysis suggested that both CCA and COD influence the CRF components. In this section, the relative influence of monthly CCA and COD on monthly CRF components are analysed over the east box region during June to September months of 2000- 2008 period. The CRF components are plotted for different CCA and COD bins for the east box for JJAS months for the 9-year analysis period (Fig.11). This figure suggests that the magnitude of the SWCRF increases as the magnitude of both COD and CCA increases. For example, at any given CCA value, magnitude of SWCRF increases as the COD increases. Similarly, for any given COD value, magnitude of SWCRF increases as CCA increases. No clear relationship is found between LWCRF and CCA/COD. As the NCRF is the sum of SWCRF and LWCRF, it is also influence by COD as well as CCA. At any particular COD or CCA value, the magnitude of the NCRF increases if the other parameters (COD for CCA) is varied. This analysis confirms that the net cooling observed over the windward sides of Madagascar mountain chain is jointly caused by COD and CCA.

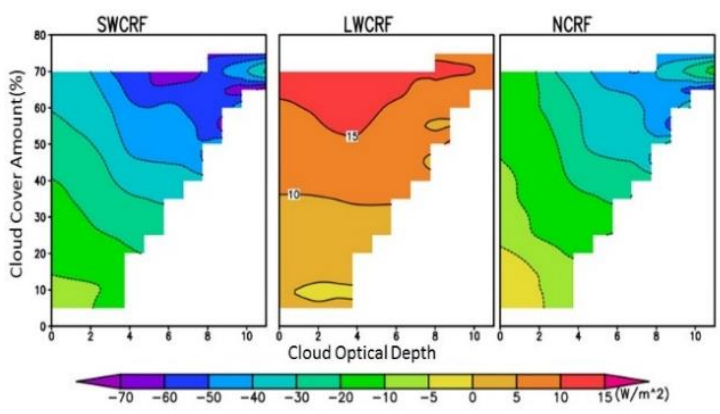

Figure 11. Variation of SWCRF, LWCRF and NCRF $\left(\mathrm{Wm}^{-2}\right)$ at diffent COD and total cloud cover (\%) bins prepared using 9 year (2000-2008) CERES and ISCCP cloud data during June-September months

\section{CONCLUSION}

Causes of formation of low level Orographic clouds on the wind ward side of the Madagascar mountain chain during June to September months is studied using 9 year ISCCP cloud data and ERA-interim reanalysis data. When the southern hemispheric moisture laden trade winds encounter the Madagascar mountain chain, they are forced to ascend and result in cloud formation due to adiabatic cooling. These clouds are unable to grow taller due to the presence the subsidence above $700 \mathrm{hPa}$. Cloud covers and cloud optical depth are more over the windward side of the Madagascar mountain than the leeward side. These orographic clouds are exerting a net radioactive cooling as high as $-35 \mathrm{Wm}^{-2}$. Close matching in the spatial pattern between COD and CRF components suggest that the radiative cooling is closely associated with COD. Relative influence of COD on CRF components are also examined. CCA influences all three components of CRF whereas COD influences SWCRF and NCRF. 


\section{REFERENCES}

Barkstrom, B. R., 1984. The Earth Radiation Budget Experiment (ERBE). Bull. Amer. Meteor. Soc., p. 11701185.

Charlock, T. P. \& Ramanathan, V., 1985. The albedo field and cloud radiative forcing produced by a general circulation model with internally generated cloud optics. J. Atmos. Sci., p. 1408-1429.

Dee, D. P. et al 2011. The ERA-interim reanalysis: configuration and per- formance of the data assimilation system. Q J R Meteorol Soc 137: 553-597. doi:10.1002/qj.828

Hartmann, D. L., Ramanathan, V., Berroir, A. \& Hunt, G. E., 1986. Earth radiation budget data and climate research. Rev Geophys, p. 439-468.

Kiehl, J. T., 1994. On the observed near cancellation between longwave and shortwave cloud radiative forcing in tropical regions. J Clim, p. 559-565.

Pai, D. S. \& Rajeevan, M., 1998. Clouds and cloud radiative forcing over tropical Indian ocean and their relationship with sea surface temperature. Curr. Sci., p. 372-381.

Rajeevan, M. \& Srinivasan, J., 2000. Net cloud radiative forcing at the top of the atmosphere in the Asian monsoon region. J Clim, p. 650-657.

Rossow , W. B., 1996. International Satellite Cloud Climatology Project (ISCCP)-Documentation of new cloud data sets WMO/ TD-737, World, s.1.: s.n.

Sathiyamoorthy, V., Pal, P. K. \& Joshi, P. C., 2004. Influence of the upper- tropospheric wind shear upon cloud radiative forcing in the Asian monsoon region. J Clim 17, p. 2725-2735.

Sathiyamoorthy, V., Pal, P. K. \& Joshi, P. C., 2007. Intraseasonal variability of the tropical easterly jet. Meteorol Atmos Phy.

Sathiyamoorthy, V., Shukla, B. P. \& Pal, P. K., 2011. A study on radiative properties of Indian summer monsoon clouds. Meteorol Atmos Phys, 19 may.

Wielicki BA, Barkstrom BR, Baum BA, Charlock TP, Green RN, Kratz DP, Lee RB III, Minnis P, Smith GL, Wong T, Young DF, Cess RD, Coakley JA, Crommelynck DAH, Donner L, Kandel R, King MD, Miller AJ, Ramanathan V, Randall DA, Stowe LL, Welch RM 1998. Clouds and the Earth's radiant energy system (CERES): algorithm overview. IEEE Trans Geosci Rem Sen 36:1127-1141. 